\title{
OPTICAL PROPERTIES OF LANTHANIDE SQUARATES
}

\author{
E. IJuskowska, J. Legendziewicz
}

Faculty of Chemistry, University of Wrocław

14 F. Joliot-Curie, 50-383 Wrocław, Poland

AND P. DRożdżEwsKi

Institute of Inorganic Chemistry and Metallurgy of Rare Elements

Technical University of Wrocław

23 Smoluchowskicgo, 50-370 Wroclaw, Poland

Two types of lantlianide squarate hydrates of formulae $\mathrm{Eu}\left(\mathrm{C}_{4} \mathrm{O}_{4}\right)\left(\mathrm{HC}_{4} \mathrm{O}_{4}\right)\left(\mathrm{H}_{2} \mathrm{O}\right)_{6} \cdot \mathrm{II}_{2} \mathrm{O}$ (compound I) and $\left[\mathrm{Ln}_{2}\left(\mathrm{C}_{4} \mathrm{O}_{4}\right)_{3}\left(\mathrm{H}_{2} \mathrm{O}\right)_{8}\right.$ ], where $\mathrm{Ln}=\mathrm{Eu}$ and $\mathrm{Gd}$ (compound II) were investigated. The optical properties of crystals I and selected spectral data of compound II are reported and confronted with earlier studies of europium complexes type II. Excitation and emission spectra were measured at $77 \mathrm{~K}$. Effect of polymeric structure on spectroscopic properties is considered and correlated with the structural data. Cooperative intrachain interactions between metal ions coupled via squarate anions were pointed and cooperative absorption was recorded. To check the presence of the $\mathrm{Eu}^{2+}$ traces, the EPR and $\gamma$-irradiation measurements were applied. Raman spectra of the compound II (where $\mathrm{Ln}=$ from Sm to $\mathrm{Lu}$ ) were measured in the range $50-500 \mathrm{~cm}^{-1}$. Positions of the bands were considered in funclion of ionic radius of lanthanide ion. The above, together with the data from excitation spectra, allows to localize the Ln-O bands. Vibronic components in electronic spectra were elucidated and assigned.

PACS numbers: $78.20 . \mathrm{Wc}, 78.20 . \mathrm{Dj}$

\section{Introduction}

Compounds of the squarate anion with many divalent and trivalent metal ions have been investigated, since they seem to have interesting structures and properties [1-5]. Most often they have polymeric structures where squarate group acts as a bridging ligand. This makes possible to study the exchange interactions between metal ions through the extended bridging groups.

During last few years, intense research of these compounds have been undertaken, first of all to study the nature of interactions occurring in polymeric two-dimensional layer structures [1].

The aim of this paper is to explain the differences observed in optical properties of two types of europium compounds, monomeric $\mathrm{Eu}\left(\mathrm{C}_{4} \mathrm{O}_{4}\right)\left(\mathrm{IC}_{4} \mathrm{O}_{4}\right)\left(\mathrm{H}_{2} \mathrm{O}\right)_{6}$. $\mathrm{H}_{2} \mathrm{O}$ (compound I) and polymeric $\left[\mathrm{Eu}_{2}\left(\mathrm{C}_{4} \mathrm{O}_{4}\right)_{3}\left(\mathrm{II}_{2} \mathrm{O}\right)_{8}\right]$ (compound II), basing on the X-ray and electronic structures. 


\section{Experimental}

Two types (I and II) of europium and gadolinium pure and diluted crystals were prepared according to the procedure described in details in [1]. Samples were checked by X-ray method. Absorption spectra were measured on a Cary-Varian 5 spectrophotometer at $293 \mathrm{~K}$. The excitation and emission spectra were recorded at $77 \mathrm{~K}$ using a SLM Aminco SPF 500 spectrofluorometer. Raman experiment was performed with a Jeol IRS-S1 double monochromator equipped with photon counting system (cooled GaAs photomultiplier). Argon laser was used as the excitation source $(\lambda=514.3$ and $488 \mathrm{~mm})$.

\section{Results and discussion}

Absorption spectra of the compound II in aqueous solution is dominated by the charge transfer $(\mathrm{C}-\mathrm{T})$ transition $(\lambda \approx 350 \mathrm{~nm}$, Fig. 1$)$ of intensity $P_{\exp }=$ $2.79 \times 10^{-3}$ (Fig. 1). Very weak $f-f$ transitions are located at the slope of the C-T band. In the same figure the absorption spectrum of isomolar solution of squaric acid is shown, where $\pi-\pi^{*}\left(A_{1 \mathrm{~g}} \rightarrow E_{\mathrm{u}}\right)$ and $n-\pi^{*}\left(A_{1 \mathrm{~g}} \rightarrow E_{\mathrm{g}}\right)$ transitions are pictured.

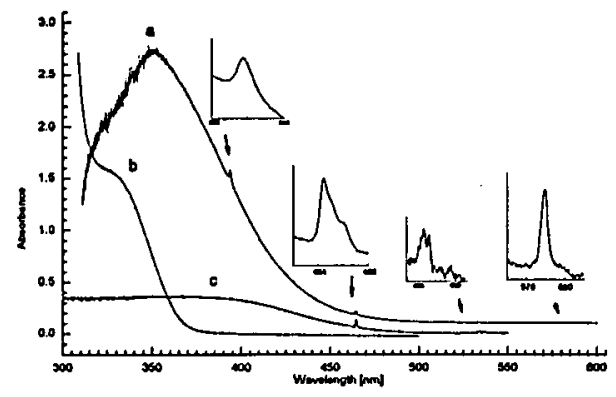

Fig. 1. Absorption spectra in the range 300-600 $\mathrm{nm}$ for: $a-$ aqueous solution of $\mathrm{Eu}_{2}\left(\mathrm{C}_{4} \mathrm{O}_{4}\right)_{3}\left(c=5 \times 10^{-3} \mathrm{M}\right.$, reference $\left.c_{s q}=7.5 \times 10^{-3} \mathrm{M}, l=5 \mathrm{~cm}\right) ; b$ - squarate solution isomolar with sample $a$ (reference $\mathrm{II}_{2} \mathrm{O}, l=5 \mathrm{~cm}$ );c- solid sample of compound II.

The broad C-T band overlaps both ${ }^{7} F_{0} \rightarrow{ }^{5} L_{6}$ and ${ }^{7} F_{0} \rightarrow{ }^{5} D_{2}$ transitions; it was also possible to detect the ${ }^{7} F_{0} \rightarrow{ }^{5} D_{1}$ and ${ }^{5} D_{0}$ transitions. In the spectrum of solid compound II the C-T band is placed at the same energy.

Let us now confront this result with the excitation spectra at $77 \mathrm{~K}$ (excitation spectra at room temperature using $4.5 \mathrm{~W}$ xenon lamp were not detectable) for both compounds. Significant differences in intensities of separated lines, as well as in population of ${ }^{7} F_{1}$ level (the strong ${ }^{7} F_{1} \rightarrow{ }^{5} D_{1}$ transition in compound II) were observed. The meaningful are, however, the changes seen in the UV region, where drastic decrease in ${ }^{7} F_{0} \rightarrow{ }^{5} L_{6}$ transition intensity in compound II was detected, whereas intensity of that transition is dominating in spectrum of compound I. Besides, the ${ }^{7} F_{0} \rightarrow{ }^{5} D_{0}$ transition in compound II is quite well recorded, while for compound I it almost vanishes. These effects registered in excitation spectra could be a result of differences in symmetry of the $\mathrm{Eu}^{3+}$ centre in both types of 
compounds, but mainly of polymeric structure of compound II (remind that compound $\mathrm{I}$ is monomeric). Moreover, the role of $\mathrm{C}-\mathrm{T}$ transition in emission quenching cannot be neglected.

To analyze the effects of $f-d$ transition of $\mathrm{Eu}^{2+}$ ion which influence both emission and excitation spectra, we made an effort to explain whether traces of $\mathrm{Eu}^{2+}$ are present in the crystal structure, as it was proposed in [2]. EPR spectra of diluted $\left(\mathrm{Gd}_{x} \mathrm{Lu}_{1-x}\right)_{2}\left(\mathrm{C}_{4} \mathrm{O}_{4}\right)_{3}$ and pure compound II were recorded at $77 \mathrm{~K}$. In contradiction to gadolinium compound, neither before nor after $\gamma$-irradiation of compound II EPR signal was detected. Thus, traces of $\mathrm{Eu}^{2+}$ were excluded.

Since some spectral effects should be caused by both intra- and interchain interactions, the EPR method was also applied to study the intrachain interactions of metal ions linked by squarate anions [6]. Judging from soft electronic structure of ligand, such interactions could occur in polymeric systems. To sensitize the interaction, mixed $\mathrm{Nd}-\mathrm{Cu}$ squarate crystals were crystallized, in which $\mathrm{Cu}$ concentration was lower than that of $\mathrm{Nd}$. Two signals of $\mathrm{Cu}^{2+}$ (at $300 \mathrm{~K}$ ) and $\mathrm{Nd}^{3+}$ (at $5 \mathrm{~K}$ ) disappear at $\approx 70 \mathrm{~K}$. This phenomenon could be explained by the $\mathrm{Nd}-\mathrm{Cu}$ intrachain interaction, most likely of superexchange type [6]. Interchain interaction of $\pi$-coupling can also occur, since squaric anions in neighboring layers are separated by $\approx 3.2 \AA$, but it needs further investigations. Those ion pairs coupled in polymeric chains can affect optical properties of the system under consideration, and probably influence the crystal colors.

Let us recognize the X-ray data. Compound I (light yellow crystals) is a monomer; environment of $\mathrm{Eu}^{3+}$ ion is composed of six water molecules and two oxygen atoms of squaric acids, whereas in compound II (intense yellow crystals) the coordination sphere of metal is formed by four $\mathrm{II}_{2} \mathrm{O}$ molecules and four oxygen atoms of bridging bidentate and tridentate squaric acids [1,3].

While the emission properties depend only on multiphonon process promoted by OII vibration modes, a stronger quenching should be observed in compound I since the energy gaps are comparable.

The differences shown in Figs. 2 and 3 are most probably caused by C-T transitions, which could take place in nonradiative deexcitation. That is why the
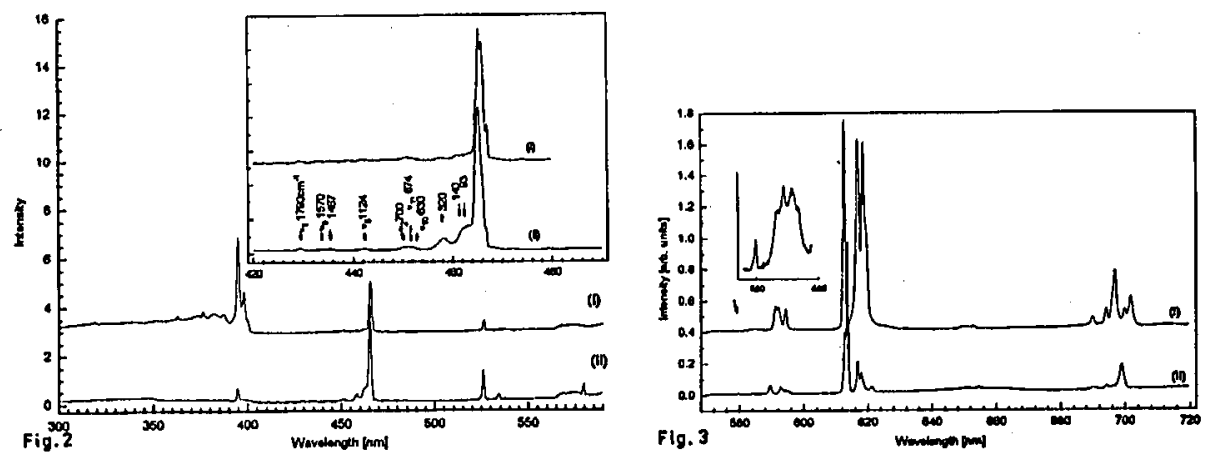

Fig. 2. Excitation spectra for the compounds I and II at $77 \mathrm{~K}$.

Fig. 3. Emission spectra of compounds I and II at $77 \mathrm{~K}$. 
drastic differences in emission intensities, differences in excitation spectra, as well as temperature dependence of emission quenching are observed. In this type of ligand, the energy transfer to europium should be expected from triplet state of ligand. Ilowever, the energy of C-T transition and relatively wide slope of its parabola lead to quenching the emission at room temperature. This situation is changed at $77 \mathrm{~K}$ and intensities of emission are much stronger.

In emission spectra, marked differences are observed in luminescence intensities (Fig. 3) and splitting of ${ }^{5} D_{0} \rightarrow{ }^{7} F_{J}$ transitions between compound I (Table I) and polymeric compound II. Therefore the $C_{2 v}$ symmetry of $\mathrm{Eu}^{3+}$ centre is predicted on the basis of group theory.

Confrontation of ${ }^{7} F_{0} \rightarrow{ }^{5} D_{2}$ transitions (Fig. 2) in the excitation spectra of both compounds demonstrates well how the optical properties are affected by polymeric structure. Besides sharp electronic lines at high energies, a rich set of vibronic components was recorded. Intensities of vibronic components for both

TABLE I

Experimental energy levels values for $\mathrm{Eu}^{3+}$ in $\mathrm{Eu}\left(\mathrm{HC}_{4} \mathrm{O}_{4}\right)\left(\mathrm{C}_{4} \mathrm{O}_{4}\right)\left(\mathrm{H}_{2} \mathrm{O}\right)_{6} \cdot \mathrm{II}_{2} \mathrm{O}$.

\begin{tabular}{|c|c|c|c|c|c|}
\hline Transition & $\begin{array}{c}\text { Energy } \\
{[\mathrm{nm}]}\end{array}$ & $\begin{array}{l}\text { Energy } \\
{\left[\mathrm{cm}^{-1}\right]}\end{array}$ & Transition & $\begin{array}{c}\text { Energy } \\
{[\mathrm{nm}]}\end{array}$ & $\begin{array}{l}\text { Energy } \\
{\left[\mathrm{cm}^{-1}\right]}\end{array}$ \\
\hline${ }^{5} D_{0} \rightarrow{ }^{7} F_{0}$ & 579.9 & 17244 & \multirow[t]{4}{*}{${ }^{5} D_{0} \rightarrow{ }^{7} F_{3}$} & 649.5 & 15396 \\
\hline \multirow{3}{*}{${ }^{5} D_{0} \rightarrow \overline{{ }^{7} F_{1}}$} & 591.3 & 16911 & & 650.3 & 15377 \\
\hline & 592.1 & 16889 & & 650.0 & 15384 \\
\hline & 594.5 & 16820 & & 651.8 & 15342 \\
\hline \multirow[t]{6}{*}{${ }^{5} D_{0} \rightarrow{ }^{7} F_{2}$} & 612.6 & 16323 & 653.1 & 15311 & \\
\hline & 616.8 & 16212 & \multirow[t]{5}{*}{${ }^{5} D_{0} \rightarrow{ }^{7} F_{4}$} & 690.0 & 14492 \\
\hline & 618.5 & 16168 & & 692.0 & 14450 \\
\hline & 619.6 & 16139 & & 694.2 & 14405 \\
\hline & 696.9 & 14349 & & 699.9 & 14287 \\
\hline & & & & 701.8 & 14249 \\
\hline
\end{tabular}

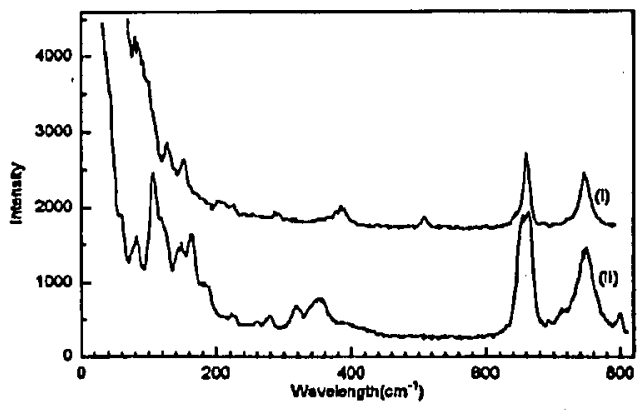

Fig. 4. Raman spectra of compounds $I$ and II in the range $0-800 \mathrm{~cm}^{-1}$. 
crystals in the region of internal ligand modes are comparable, but the drastic differences are scen in the range of $0-450 \mathrm{~cm}^{-1}$ from 0 -phonon lines, where cooperative interaction is considered (Table II). Enhancement of intensities of some lines in the spectrum of compound II $\left(\approx 330-350 \mathrm{~cm}^{-1}\right)$ is due to cooperative absorption of coupled $\mathrm{Eu}^{3+}$ pairs in the polymeric chain, most likely mediated by phonons of energy close to splitting of the ${ }^{7} F_{0} \rightarrow{ }^{7} F_{1}$ level. Moreover, the second line can overlap that mentioned above at $279 \mathrm{~cm}^{-1}$, which remains in resonance with the first Stark component of ${ }^{7} F_{1}$ level (see note of Table II). Cooperative absorption was earlier observed by Buys et al. [7].

TABLE II

Vibronic components in the excitation $\left({ }^{7} F_{0} \rightarrow{ }^{5} D_{2},{ }^{7} F_{0} \rightarrow{ }^{5} D_{2}\right)$ and luminescence $\left({ }^{5} D_{0} \rightarrow{ }^{7} F_{0}\right)$ spectra of $\mathrm{Eu}\left(\mathrm{C}_{4} \mathrm{O}_{4}\right)\left(\mathrm{IIC}_{4} \mathrm{O}_{4}\right)\left(\mathrm{H}_{2} \mathrm{O}\right)_{6} \cdot \mathrm{H}_{2} \mathrm{O}(\mathrm{I})$ and $\mathrm{Eu}_{2}\left(\mathrm{C}_{4} \mathrm{O}_{4}\right)_{3}\left(\mathrm{II}_{2} \mathrm{O}\right)_{8}$ (II).

\begin{tabular}{c|c|c|c|c|c}
\hline \hline \multirow{2}{*}{ Transition } & \multicolumn{2}{|c|}{ Compound I } & \multicolumn{2}{c|}{ Compound II } & \multirow{2}{*}{ Assignment ${ }^{c}$} \\
\cline { 2 - 5 } & $\begin{array}{c}\text { Energy } \\
{[\mathrm{nm}]}\end{array}$ & $\begin{array}{c}\Delta E \\
{\left[\mathrm{~cm}^{-1}\right]}\end{array}$ & $\begin{array}{c}\text { Energy } \\
{[\mathrm{nm}]}\end{array}$ & $\begin{array}{c}\Delta E \\
{\left[\mathrm{~cm}^{-1}\right]}\end{array}$ & \\
\hline${ }^{5} D_{0} \rightarrow{ }^{7} F_{0}$ & $\frac{579.9^{a}}{}$ & & $\frac{579.7^{a}}{}$ & & \\
(comp. I) & 583.3 & 101 & $579.2^{a}$ & & \\
or & 584.4 & 133 & & & \\
${ }^{7} F_{0} \rightarrow{ }^{5} D_{0}$ & 585.5 & 165 & 574.3 & 164 & $\delta_{\text {Me-O }}$ \\
$($ comp. II) & 586.7 & 200 & 572.4 & 222 & \\
& & & 568.9 & 329 & \\
\hline${ }^{7} F_{0} \rightarrow{ }^{5} D_{2}$ & $466.9^{a}$ & & $467.9^{a}$ & & \\
& $466.0^{a}$ & & $465.9^{a}$ & & \\
& $465.3^{a}$ & & $465.1^{a}$ & & \\
& $464.7^{a}$ & & $464.8^{a}$ & & \\
& 463.2 & 97 & 463.1 & 93 & \\
& 460.9 & 205 & 461.9 & $151279^{b}$ & \\
& 457.7 & 357 & 458.1 & 329 & \\
& 452.6 & 603 & 451.9 & 630 & $\nu_{10}$ \\
& & & 451.0 & 674 & $\nu_{11}$ \\
& 450.8 & 691 & 450.4 & 700 & $\nu_{2}$ \\
& 441.8 & 1133 & 442.0 & 1123 & $\nu_{5}$ \\
& 435.3 & 1481 & 435.4 & 1466 & \\
& 432.9 & 1609 & 433.7 & 1560 & $\nu_{9}$ \\
& 429.2 & 1808 & 429.4 & 1790 & $\nu_{1}$ \\
\hline
\end{tabular}

${ }^{a}$ Electronic lines; underlined those for which $\Delta E$ was calculated. ${ }^{b} \Delta$ calculated from line $467.9 \mathrm{~nm}$. Energy gaps between ${ }^{7} F_{0}$ and Stark components of ${ }^{7} F_{1}$ for compound II are as follows: 288,303 , 383,415 and $450 \mathrm{~cm}^{-1}$.

c Notation as in $[8,9]$. 
TABLE III

Position of Raman bands for lanthanide $\mathrm{Ln}_{2}\left(\mathrm{C}_{4} \mathrm{O}_{4}\right)_{3}\left(\mathrm{H}_{2} \mathrm{O}\right)_{8}$ complexes in the region $0-500 \mathrm{~cm}^{-1}$ as a function of ionic radius of lanthanide ion.

\begin{tabular}{|c|c|c|c|c|c|c|c|c|c|}
\hline$\overline{L n}$ & $r[\mathrm{pm}]$ & \multicolumn{8}{|c|}{ Frequency $\left[\mathrm{cm}^{-1}\right]$} \\
\hline \multirow[t]{2}{*}{$\overline{\mathrm{Lu}}$} & 97 & 37 & 56 & 71 & 82 & 109 & 120 & 148 & 170 \\
\hline & & 190 & 240 & 283 & 338 & 360 & 410 & 440 & \\
\hline \multirow[t]{2}{*}{$\mathrm{Yb}$} & 98 & 37 & 56 & 71 & 82 & 109 & 118 & 147 & 168 \\
\hline & & 189 & 240 & 283 & 335 & 359 & 410 & 440 & \\
\hline \multirow[t]{2}{*}{ IIo } & 102 & 36 & 55 & 70 & 80 & 104 & 115 & 144 & 164 \\
\hline & & 186 & 228 & 280 & 329 & 356 & 404 & 436 & \\
\hline \multirow[t]{2}{*}{ Dy } & 103 & 36 & 56 & 70 & 79 & 104 & 114 & 145 & 162 \\
\hline & & 184 & 226 & 278 & 322 & 352 & 400 & 430 & \\
\hline \multirow[t]{2}{*}{$\mathrm{Tb}$} & 104 & 36 & 56 & 70 & 80 & 103 & 114 & 145 & 161 \\
\hline & & 183 & 226 & 278 & 321 & 351 & 402 & 428 & \\
\hline \multirow[t]{2}{*}{$\mathrm{Gd}$} & 106 & 37 & 57 & 70 & 80 & 104 & 113 & 143 & 158 \\
\hline & & 180 & 222 & 275 & 317 & 350 & 395 & 422 & \\
\hline \multirow[t]{2}{*}{$\mathrm{Eu}$} & 107 & 36 & 56 & 70 & 78 & 103 & 111 & 144 & 156 \\
\hline & & 180 & 220 & 273 & 315 & 347 & 386 & 414 & \\
\hline \multirow[t]{2}{*}{$\mathrm{Sm}$} & 109 & 37 & 57 & 70 & 79 & 103 & 110 & 143 & 155 \\
\hline & & 178 & 214 & 274 & 311 & 344 & 380 & 415 & \\
\hline
\end{tabular}

Comparison of the electronic spectra with Raman data $\left(30-800 \mathrm{~cm}^{-1}\right)$ for both types of compounds seems spectacular (Fig. 4). The differences are observed for the $b_{2 \mathrm{~g}}$ symmetry vibrational species of squarate anion (effective in the JahnTeller effect) and in the $a_{1 \mathrm{~g}}$ symmetry vibrations, as well as in vibrational mode of $\mathrm{MO}_{8}$ coordination clusters and lattice phonons. It is not an intention of the authors to perform full vibrational analysis but, basing on available vibrational assignments for $\mathrm{C}_{4} \mathrm{O}_{4}^{2-}$ anion $[8,9]$, the vibronic components in electronic transitions are analyzed and listed in Table II. Vibrational frequencies of sample II correspond quite well to those reported by Ribeiro et al. [2].

Note also significant differences in the $200-400 \mathrm{~cm}^{-1}$ range, where complex structure of bands is observed, especially for compound II. Among these lines, basing on careful analysis of Raman spectra of compound II with lanthanides from Sm to Lu, two frequencies between $214-240 \mathrm{~cm}^{-1}$ and $311-338 \mathrm{~cm}^{-1}$ (Table III) are the most sensitive to changes in metal ionic radii. It makes possible, together with the analysis of strong vibronic components in excitation spectra, to localize the Eu-O involved modes at 220 and/or $315(\nu)$ and $156(\delta) \mathrm{cm}^{-1}$ for the compound II.

\section{Conclusions}

Absorption spectra of europium squarate in aqueous solution show C-T transition with maximum at $350 \mathrm{~nm}\left(P_{\exp }=2.79 \times 10^{-3}\right)$. It is located at similar 
energy as $n \rightarrow \pi^{*}$ transition of the ligand, and plays an important role in emission properties of the europium ion.

Confrontation of two types of europium squarates allows to point out the role of polymeric structure in emission properties, indicating strong cooperative absorption at $\approx 330$ and $280 \mathrm{~cm}^{-1}$. EPR measurements confirm superexchange interaction of ionic pairs coupled in polymeric chain [6]. The EPR and $\gamma$-irradiation experiments excluded presence of the traces of $\mathrm{Eu}^{2+}$ ions in the structure.

Analysis of the positions of the Raman bands for the series of polymeric lanthanide squarates of formula $\mathrm{Ln}_{2}\left(\mathrm{C}_{4} \mathrm{O}_{4}\right)_{3}\left(\mathrm{II}_{2} \mathrm{O}\right)_{8}$, together with positions of strong vibronic components of excitation spectrum of $\mathrm{Eu}^{3+}$ allows to localize the metal-oxygen involved vibrations at 220 and/or $315(\nu)$ and $156 \mathrm{~cm}^{-1}(\delta)$.

\section{Acknowledgments}

This paper was sponsored by the Committee for Scientific Research, grant PB1254/P3/96/02.

\section{References}

[1] E. IIuskowska, T. Glowiak, J. Legendziewicz, G. Oremek, J. Alloys Comp. 179, 13 (1992).

[2] S.J.L. Ribeiro, R.R. Goncalves, L.F.C. de Oliveira, P.S. Santos, J. Alloys Comp. 216, 61 (1994).

[3] J.-F. Petit, A. Gleizes, J.-Ch. Trombe, Inorg. Chim. Acta 167, 51 (1990).

[4] J.-Ch. Trombe, J.-F. Petit, A. Gleizes, Inorg. Chim. Acta 167, 68 (1990).

[5] L.F.C. Piriou, J.F. Petit, J.-Ch. Trombe, A. Gleizes, J. Chem. Phys. 86, 1207 (1989).

[6] V.K. Voronkova, Yu.V. Yablokov, E. IIuskowska, J. Legendziewicz, in: Proc. Winter Workshop on Coord. Chem., Karpacz (Poland) 1995, Ed. B. Żurowska, Faculty of Chemistry, Wrocław University, Wrocław 1995, p. 65.

[7] M. Buys, A. Meyerink, G. Blasse, J. Lumin. 37, 9 (1987).

[8] M. Ito, R. West, J. Am. Chem. Soc. 85, 2580 (1963).

[9] M. Iijima, Y. Udagawa, K. Kaya, M. Ito, Chem. Phys. 0, 229 (1975). 